\title{
A NEW DETERMINATION OF THE ELECTROMOTIVE FORCE OF WESTON AND CLARK STANDARD CELLS BY AN ABSO- LUTE ELECTRODYNAMOMETER.
}

\author{
By Karl E. Guthe.
}

\section{INTRODUCTION.}

Since our practical electromagnetic units are based upon the c. g. s. system, and in some countries are defined in terms of the units of the latter, ${ }^{1}$ it is of the greatest importance to have the relation between the two systems determined with as great accuracy as possible. By a series of classical experiments ${ }^{2}$ the absolute value of the ohm = Io c. g. s. units has been determined with a probable error of $I$ in 5,000 , and based upon the value thus found a practical unit, the mercury ohm, is now in general use, and can probably be reproduced with an accuracy of $I$ in $50,000 .^{3}$

There remain the electromotive force and the current. The evaluation of the former in electrostatic measure and consequent reduction to electromagnetic units by means of the ratio between these two systems can not give us very reliable results so long as the above ratio has not been determined with a greater accuracy than that obtained up to the present time. It has, however, the advantage of being a direct determination-i. e., one in which no other electrical units have been used-provided the ratio of the two systems is independently determined. Electromotive force may also be measured indirectly as the difference of potential produced by a known current at the terminals of a known resistance. Its determination is thus closely related to that of an electric current,

\footnotetext{
${ }^{1}$ Wolff; this Bulletin, 1, 39; I904.

${ }^{2}$ Dorn, Zs. für Instrumentenkunde, 23, appendix, I893.

${ }^{3}$ Jaeger, Sitzungsberichte der K. P. Akademie der Wissenschaften (Berlin), 25, p. 547; I903. Smith, Phil. Trans. Roy. Soc. A, 204, p. II4; I904.
} 
but introduces at the same time any error present in the absolute value of the ohm. This method leads, however, to more reliable results than the one before mentioned, and has therefore been frequently used for the determination of the electromotive force of standard cells. The problem is then to construct an apparatus which will allow a calculation of the current flowing through it from the electromagnetic effects which it produces. This same current may, of course, be used also for the determination of the electrochemical equivalent of silver or of any other suitable metal. This would be an absolute determination; it would, however, require the use of the current for the whole time the silver is deposited in the coulometer, and therefore it is simpler to determine first the electromotive force of a standard cell and then calculate the electrochemical equivalent from an independent series of experiments. This enables one to determine the relation between the two with an accuracy much greater than is obtainable with the absolute instrument. The problem of determining the absolute value of an electromotive force or the electrochemical equivalent of silver is thus reduced to the absolute measurement of current. We may divide the various methods and types of instruments proposed for this purpose into two large classes: (A) Electromagnetic methods, in which the action between the magnetic field of the earth and the current, or that between the current and the known moment of a magnet is measured by means of standard galvanometers or by means of the electromagnetic balance. (B) Electrodynamic methods, characterized by an action between two magnetic fields which are both produced by the same current. The instruments used in these latter methods are current balances and electrodynamometers.

\section{ELECTROMAGNETIC METHODS.}

After having been proposed by $\mathrm{W}$. Weber ${ }^{1}$ for the absolute measurement of current in I840 the tangent galvanometer has been frequently employed for this purpose, especially by Bunsen, Casselmann, and Joule, and in more recent times by Fr. and W. Kohlrausch ${ }^{2}$ and by Van Dijk and Kunst. ${ }^{3}$ These last four observers have obtained

${ }^{1}$ Weber; Pogg. Annal. 55, 27; I842.

${ }^{2}$ Fr. and W. Kohlrausch; Pogg. Annal. 149, I $70 ;$ i 886.

${ }^{3}$ Van Dijk and Kunst, Proc. Roy. Acad. Amsterdam, I904, Annalen der Physik 14. 569 ; 1904 . 
very satisfactory results for the electrochemical equivalent of silver; but besides the large number of correction factors to be taken into account, the method necessitates an accurate knowledge of the horizontal intensity of the earth's magnetic field expressed in c. g.s. units and its variation during the progress of the experiment. Even with no outside disturbances $H$ can not be measured more accurately than to about $\mathrm{I}$ in $4,000 .{ }^{1}$ The same criticism applies to all other forms of instruments belonging to this general group-for example, the Gaugain-Helmholtz and the Gray types of the tangent galvanometer, and the sine, cosine, and bifilar galvanometers. The results with the electromagnetic balance are to be trusted still less. ${ }^{2}$

\section{ELECTRODYNAMIC METHODS.}

In the current balance the electrodynamic action between two coils carrying the current to be measured is balanced by known weights. The first balance constructed for this purpose was that of Cazin (1863), who determined by means of it the electrochemical equivalent of water. In England, ${ }^{3}$ France, ${ }^{4}$ and Germany, ${ }^{5}$ instruments of this type have been used, and while the French results differ considerably from those obtained in the other countries, this method is doubtless of great value. The acceleration due to gravity can be determined with an accuracy of $\mathrm{I}$ in $20,000{ }^{6}$ and with an apparatus whose dimensions are easily determined-for instance, with coils of a single layer very reliable results can be expected. Such determinations are being carried out at present at the National Physical Laboratory in England.

The electrodynamometer was proposed for absolute measurements by W. Weber, and an instrument with two stationary coils at a distance equal to their mean radius (as proposed by von Helmholtz) was constructed by the Committee on Electrical Standards of the British Association. This apparatus was first used by L. Clark ${ }^{7}$

\footnotetext{
${ }^{1}$ Bauer; Science, 22, 16; 1905.

${ }^{2}$ Koepsel; Wied. Annalen, 31, 250; I887.

${ }^{3}$ Rayleigh and Sidgwick; Phil. Trans. Roy. Soc. 175, 4 II; I884.

${ }^{4}$ Mascart; Journal de Physique, 1, Io9; I882. Potier and Pellat, Journal de Physique, 9, 38r; I89o. Pellat and Leduc, Comptes Rendus, 136, p. I649; I903.

${ }^{5}$ Kahle, Wied. Annalen, 59, 532; 1896.

${ }^{6}$ Jahresber. Dir. Preuss. Geod. Inst., I904. p. 26.

${ }^{7}$ Clark, Phil. Trans. Roy. Soc. 164, I; I874.
} 
for the measurement of the emf. of the Clark standard cell, and a similar instrument was employed by R. O. King. ${ }^{1}$ A type of electrodynamometer with coils of a single layer of wire was proposed by A. Gray. ${ }^{2}$ Such an instrument was constructed by Patterson and Guthe $^{3}$ for the determination of the electrochemical equivalent of silver, and also used by Carhart and Guthe ${ }^{4}$ for the measurement of the emf. of the Clark cell. In these cases the electromagnetic effect of the two coils upon one another was balanced by the torsional moment of a single wire, whose mechanical properties were determined by preliminary experiments. In the following table are given the most reliable results obtained by absolute methods, the values for the silver equivalent being reduced to those which would have been found in a silver coulometer of the porous cup type. ${ }^{5}$ This correction is necessary, since different experimenters have used different types and consequently obtained results which can not be directly compared with each other. The mercurous sulphate of the Clark cells cited was prepared in the well-known chemical way, the emf. being reduced to $15^{\circ} \mathrm{C} .{ }^{6}$

\section{TABLE I.}

Electrochemical Equivalent of Silver.

\begin{tabular}{lcll}
\multicolumn{1}{c}{ Observer. } & Year. & \multicolumn{1}{c}{ Instrument. } & \multicolumn{2}{c}{ E1.-chem. Equiv. } \\
Fr. and W. Kohlrausch & 1884 & Tangent galvanometer & 0.0011177 gram. \\
Rayleigh and Sidgwick & 1884 & Current balance & 0.0011176 " \\
Potier and Pellat & 1890 & Current balance & 0.0011189 "6 \\
Patterson and Guthe & 1898 & Electrodynamometer & 0.0011177 \\
Pellat and Leduc & 1903 & Current balance & 0.0011190 " \\
Van Dijk and Kunst & 1904 & Tangent galvanometer & 0.0011178 "
\end{tabular}

Electromotive Force of the Clark Standard Cell.

$\begin{array}{llll}\text { Rayleigh and Sidgwick } & 1884 & \text { Current balance } & 1.4345 \text { volts. } \\ \text { Kahle } & 1896 & \text { Current balance } & 1.4322 \text { "6 } \\ \text { Carhart and Guthe } & 1899 & \text { Electrodynamometer } & 1.4333 \text { " }\end{array}$

The values obtained by the author in his work with Professors Carhart and Patterson showed that the electrodynamometer method

${ }^{1}$ Callendar, Trans. Roy. Soc. 8I, 199, I902.

${ }^{2}$ Gray, Absolute Measurements, 2, pt. I, 274.

${ }^{3}$ Patterson and Guthe, Physical Review, 7, 257; r898.

${ }^{4}$ Carhart and Guthe, Physical Review, 9, 288; I899.

${ }^{5}$ Guthe, this Bulletin, 1, p. 363 ; 1905.

${ }^{6}$ Centigrade scale is used throughout this paper. 
is well adapted to work of this kind. In the former investigations, however, the actual number of determinations was small, and it seemed therefore advisable to repeat them with an instrument of improved construction and after a more thorough investigation of the various factors entering into the calculation, especially of the elastic properties of the suspension used, and the influence of irregularity of winding upon the field inside the coil.

\section{THE ELECTRODYNAMOMETER.}

As was first pointed out by Gray ${ }^{1}$ the expression for the torque between the two coils of an electrodynamometer assumes a simple form if the dimensions of both coils are chosen so that the length and the radius are in the proportion $\sqrt{3}: \mathrm{I}$, if their centers coincide and, finally, if the dimensions of the fixed coil are large in comparison with those of the movable. Under these conditions the expression for the torque between the two coils with their axes at right angles to each other becomes

$$
T=\frac{4 \pi^{2} N n r^{2}}{\sqrt{D^{2}+L^{2}}} I^{2}
$$

where $N$ and $n$ are the number of turns in the stationary and movable coils, $D$ and $L$ the diameter and length of the stationary, $r$ the radius of the movable coil and $I$ the current, expressed in c. g. s. units.

In the construction of the apparatus the conditions laid down above were closely followed. A calculation of the correction terms due to slight deviation from these conditions showed that they were entirely negligible.

\section{THE STATIONARY COIL.}

The frame of the stationary coil was made of plaster of Paris. ${ }^{2}$ Experiments carried on in Ann Arbor, in conjunction with Professors Carhart and Patterson, and which led to the construction of a new instrument while the author was still at that place, showed the great superiority of this material over wood as used in our first instrument. If sufficient care is exercised in the preparation of the mixture of plaster of Paris and water it is easy to make cylinders

\footnotetext{
${ }^{1}$ Gray, 1. c.

${ }^{2}$ The instrument was constructed by Mr. Rudolph Hellbach of this Bureau, to whom I am indebted for valuable assistance in the solution of mechanical difficulties.
} 
of any desired size. Plaster of Paris is, as will be shown, nonmagnetic, and while not as hard as marble (an advantage, so far as working it is concerned) it is sufficiently so for the purpose. The cylinder made at the Bureau of Standards was about $55 \mathrm{~cm}$ long and had a diameter of a little more than $55 \mathrm{~cm}$ and a wall thickness of about $10 \mathrm{~cm}$. The larger air holes, from which it was remarkably free, were filled in and the whole cylinder soaked in melted paraffin before being turned. It was first turned on a large lathe, but after the cylinder was removed from the chucks it was found to have sprung and the ends were slightly elliptical. It was then finished on one of the boring mills at the United States Navy-Yard at Washington. On this machine it stands on end and is therefore not subjected to internal strains.

The diameter was measured by means of a large caliper, specially constructed of nickel iron in order to minimize the temperature changes due to handling it. The readings of the caliper were compared with those on a Brown and Sharpe steel end standard whose length was determined by the division of Weights and Measures to be $50.0055 \mathrm{~cm}$ at $25^{\circ}$ with a temperature coefficient equal to o.0000II.

While still on the table of the boring mill seven equidistant pencil lines were drawn on the circumference, the outer ones being $5 \mathrm{~cm}$ from the edge. These circles were numbered o, I, II, III, etc., and were divided by 24 straight lines, drawn parallel to the axis, into two sets of equal arcs of $30^{\circ}$. These lines were marked o, I, 2,3 , etc., and $\mathrm{o}^{\prime}, \mathrm{I}^{\prime}, 2^{\prime}, 3^{\prime}$, etc., respectively. We were thus enabled to determine the exact location of the opposite ends of a given diameter by the intersection with one of the circles of two lines $180^{\circ}$ apart; thus 84 diameters were located and their lengths measured by three observers, who divided the work so that one of them took one set of 42 diameters, one the other set, and the third one half of each. Each observation was the mean of three readings, making the total number of readings equal to 378 .

The results are very satisfactory; the mean diameters as determined by the three observers and reduced to $25^{\circ}$, being:

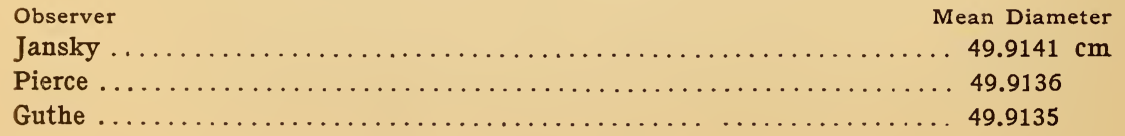


In each circle the readings of the different diameters agreed within $0.03 \mathrm{~mm}$, and the average diameter for the different circles along the cylinder shows only the very slight increase of $0.05 \mathrm{~mm}$ from one end to the other.

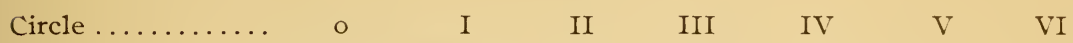

$\begin{array}{lllllll}\text { Diameter cm....... 49.9III } & 49.9 \text { I2I } & 49.9 I 40 & 49.9 I 37 & 49.9 I 46 & 49.9140 & 49.9163\end{array}$

The average diameter of the plaster-of-Paris frame for the stationary coil is therefore $49.9 \mathrm{I} 37 \mathrm{~cm}$ at $25^{\circ}$.

In order to determine the temperature coefficient of the cylinder it was transferred to the refrigerating room of the Bureau of Standards and the mean diameter measured at a lower temperature. The thermometer was placed, as in the above experiments, in a hole drilled in the side halfway between the outer and the inner surface. On account of the temperature variations of the room the temperature indicated by the thermometer might not have been the average temperature of the cylinder; nevertheless, it gives us an approximate value for the expansion of plaster of Paris.

At $\mathrm{I} 2^{\circ}$ the average diameter was found to be $49.8976 \mathrm{~cm}$, giving the coefficient of expansion of the cylinder as 0.000025 . In the absolute determinations the temperatures were always in the neighborhood of 25 degrees, and hence a small error in the temperature coefficient could have no appreciable effect upon the final result.

The cylinder was then carefully wound with a single layer of double silk-covered wire of diameter equal to $0.0495 \mathrm{~cm}$. Instead of a single wire, however, two separate wires were wound side by side at the same time so that each turn of one would lie between two of the other. This was done in order to enable us to determine the insulation resistance of the completed instrument by measuring the resistance between the two wires.

The measurements of the mean diameter were now repeated and resulted in a value equal to $50.01 \mathrm{I} 2 \mathrm{~cm}$ at $25^{\circ}$. The current flowing through the coil may be assumed to be concentrated at the center of the wire so that we obtain for the effective diameter of the stationary coil $D=49.9624 \mathrm{~cm}$.

After the measurements had been completed the coil was given three coats of shellac. 
For completeness I shall add one of the sets of measurements on 42 diameters, each being the mean of three readings, in order to show how accurately cylindrical the coil is.

TABLE II.

Showing 42 Diameters of the Cylinder.

\begin{tabular}{l|r|r|r|r|r|r}
\hline & \multicolumn{1}{|c|}{$0^{\prime}$} & \multicolumn{1}{c|}{$I^{\prime}$} & \multicolumn{1}{c}{$2^{\prime}$} & \multicolumn{1}{c}{$3^{\prime}$} & \multicolumn{1}{c}{$4^{\prime}$} & \multicolumn{1}{c}{$5^{\prime}$} \\
\cline { 2 - 3 } 0 & 50.0108 & 50.0119 & 50.0098 & 50.0101 & 50.0100 & 50.0127 \\
I & .0083 & .0094 & .0124 & .0089 & .0102 & .0121 \\
II & .0129 & .0119 & .0108 & .0092 & .0102 & .0116 \\
III & .0095 & .0113 & .0099 & .0129 & .0098 & .0099 \\
IV & .0089 & .0116 & .0109 & .0092 & .0113 & .0090 \\
V & .0109 & .0108 & .0113 & .0118 & .0108 & .0105 \\
VI & .0114 & .0108 & .0097 & .0103 & .0106 & .0124 \\
\hline
\end{tabular}

\section{LENGTH OF STATIONARY COIL.}

The total number of turns of wire on the stationary coil was 872 , and although great pains were taken to make the winding as uniform as possible we did not succeed in making it perfectly uniform, since there was no lathe at our disposal big enough to hold the cylinder and besides we did not wish to subject it to new strains. The winding was therefore done entirely by hand, and the irregularity of winding was taken into account in determining the strength of the magnetic field at the center of the coil. The cylinder was placed on end, leveled, and a steel scale subdivided to $0.2 \mathrm{~mm}$ placed parallel to the axis so as to touch the wires along one of the lines marked on the cylinder before it was wound. Then, by means of a cathetometer, whose short-focused telescope moved parallel to the line of contact between scale and coil, the space covered by 50 turns was measured successively along the line. In this way an accurate knowledge of the irregularity of the windings along $\mathrm{I} 2$ lines parallel to the axis and 30 degrees apart was obtained. The results are embodied in the following table: 
Guthe.] Absolute Electromotive Force of Standard Cells.

TABLE III.

Length of 50 Turns Along the Lines.

\begin{tabular}{|c|c|c|c|c|c|c|}
\hline $\begin{array}{l}\text { Number of } \\
\text { Turns }\end{array}$ & $\mathbf{x}^{\prime}$ & $2^{\prime}$ & $3^{\prime}$ & $4^{\prime}$ & $5^{\prime}$ & $6^{\prime}$ \\
\hline $0-50$ & $24.867 \mathrm{~mm}$ & 24.895 & 24.900 & 24.829 & 24.892 & 24.942 \\
\hline $50-100$ & .909 & .919 & .944 & .971 & .924 & .935 \\
\hline $100-150$ & . .960 & .962 & .965 & .996 & .958 & 25.029 \\
\hline $150-200$ & .887 & .814 & .870 & .804 & .951 & 24.882 \\
\hline $200-250$ & .921 & .773 & .892 & .888 & .864 & .962 \\
\hline $250-300$ & .774 & .556 & .780 & .823 & .749 & .756 \\
\hline $300-350$ & .600 & .545 & .652 & .591 & .641 & .621 \\
\hline $350-400$ & .688 & .634 & .730 & .698 & .670 & .712 \\
\hline $400-450$ & .680 & .658 & .647 & .705 & .733 & .676 \\
\hline $450-500$ & .600 & .746 & .614 & .595 & .581 & .623 \\
\hline $500-550$ & .527 & .637 & .539 & .532 & .511 & .577 \\
\hline $550-600$ & .606 & .793 & .517 & .622 & .581 & .542 \\
\hline $600-650$ & .724 & .896 & .765 & .768 & .788 & .852 \\
\hline $650-700$ & .794 & .942 & .791 & .814 & .781 & .800 \\
\hline $700-750$ & .911 & .990 & .962 & .968 & .949 & 25.029 \\
\hline $750-800$ & .928 & .915 & .932 & 25.000 & .940 & 24.965 \\
\hline $800-850$ & .910 & .915 & .903 & 24.926 & .889 & .959 \\
\hline $850-872$ & 11.063 & $\ldots$ & 11.059 & 11.200 & 11.047 & 11.085 \\
\hline $\begin{array}{c}\text { Number of } \\
\text { Turns }\end{array}$ & $7^{\prime}$ & $8^{\prime}$ & $9^{\prime}$ & Io' & $\mathrm{II}^{\prime}$ & $\mathrm{o}^{\prime}$ \\
\hline $0-50$ & $24.985 \mathrm{~mm}$ & 24.937 & 25.003 & 25.076 & 25.023 & 24.894 \\
\hline $50-100$ & .929 & .949 & 24.921 & 24.939 & 24.939 & .909 \\
\hline $100-150$ & .956 & .939 & .930 & .950 & .965 & .953 \\
\hline $150-200$ & .898 & .821 & .900 & .844 & .867 & .841 \\
\hline $200-250$ & .864 & .708 & .876 & .815 & .892 & .939 \\
\hline $250-300$ & .727 & .703 & .685 & .747 & .737 & .758 \\
\hline $300-350$ & .591 & .578 & .647 & .603 & .682 & .644 \\
\hline $350-400$ & .703 & .697 & .692 & .724 & .698 & .732 \\
\hline $400-450$ & .703 & .699 & .705 & .764 & .683 & .668 \\
\hline $450-500$ & .632 & .683 & .733 & .865 & .657 & .598 \\
\hline $500-550$ & .574 & .681 & .632 & .624 & .632 & .597 \\
\hline $550-600$ & .580 & .728 & .665 & .547 & .552 & .549 \\
\hline $600-650$ & .690 & .878 & .849 & .735 & .744 & .762 \\
\hline $650-700$ & .812 & .922 & .780 & .768 & .841 & .800 \\
\hline $700-750$ & .983 & .956 & .997 & 25.009 & .974 & 25.017 \\
\hline $750-800$ & .950 & .995 & .959 & 24.927 & .937 & 24.977 \\
\hline $800-850$ & .950 & .968 & .965 & .959 & .962 & .953 \\
\hline $850-872$ & 11.070 & $\ldots$ & 11.188 & 11.053 & 11.025 & 11.044 \\
\hline
\end{tabular}


As will be seen from this table the measurements on the 12 lines show a close agreement as to the distribution of the turns along the coil. This comes out very distinctly in plotting the $\mathrm{I} 2$ different values for the corresponding numbers and it is therefore admissible to take the mean of all to represent the irregularity of winding. This gives us Table IV and the broken curve in Fig. I where the space occupied by 50 turns is plotted as a function of the distance from one end.

The winding is somewhat closer in the middle than at the ends, the curve being to a certain extent symmetrical about the center.

The value found by measurement for the average length of the coil has to be corrected for the error of the steel scale between the

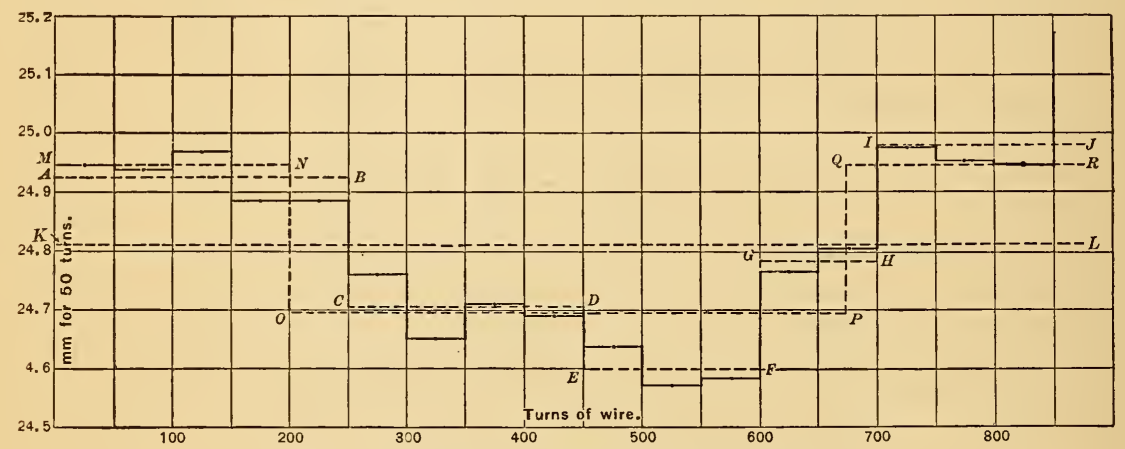

Fig. 1.-Irregularity of Winding of Stationary Coil.

two points used in these measurements. The correction was found by the division of Weights and Measures to be $+0.057 \mathrm{~mm}$ at the temperature at which it was used. The average length of the coil is therefore at $25^{\circ} \mathrm{L}=43.2764 \mathrm{~cm}$. The length calculated from the theoretical relation between length and radius would be $43.32 \mathrm{~cm}$.

In correcting for the irregularity of winding I substituted for the actual coil two layers of uniform winding, superposed one upon the other, the first to be of the same average length as the coil, the second, a shorter one, at the center. As the length of the latter the distance between two points where the density of the winding considerably increased was selected. The short coil was assumed to have a length equal to the distance between the 2ooth and the $672 \mathrm{~d}$ turns, i. e., the density of winding of the longer coil to be the average of that of the 400 outer turns represented by $M N$ and $Q R$, Fig. I. This average gives for the space covered by 50 turns 
$24.946 \mathrm{~mm}$ and the total number of turns in the longer coil $(432.764 / 24.946) \times 50=867.40$ turns. This leaves 4.60 turns for the smaller coil, distributed over $233.196 \mathrm{~mm}$; or 872 turns in all.

TABLE IV.

Mean Length of 50 Turns.

\begin{tabular}{c|c|c}
\hline Number of Turns & Length of 50 Turns & Corrected \\
\hline $0-50$ & $24.941 \mathrm{~mm}$ & $24.945 \mathrm{~mm}$ \\
$50-100$ & .936 & .940 \\
$100-150$ & .967 & .970 \\
$150-200$ & .884 & .887 \\
$200-250$ & .884 & .887 \\
$250-300$ & .755 & .758 \\
$300-350$ & .649 & .652 \\
$350-400$ & .706 & .709 \\
$400-450$ & .693 & .696 \\
$450-500$ & .636 & .639 \\
$500-550$ & .572 & .575 \\
$550-600$ & .585 & .588 \\
$600-650$ & .763 & .766 \\
$650-700$ & .801 & .804 \\
$700-750$ & .975 & .978 \\
$750-800$ & .949 & .953 \\
$800-850$ & .942 & .946 \\
$850-872$ & 11.069 & 11.071 \\
\hline $0-872$ & 432.707 & 432.764 \\
\hline
\end{tabular}

The strength of the magnetic field at the center of the coil is expressed by the formula

$$
H=\frac{4 \pi N I}{\sqrt{D^{2}+L^{2}}}=C I
$$

where $N$ is the number of turns, $D$ the diameter and $L$ the length of the coil, and in the following the constant $C$ for each of the two coils is given.

$\mathrm{C}_{1}$ due to the long coil $=\mathrm{I} 64.905$

$\mathrm{C}_{2}$ due to the short coil $=\quad \mathrm{I.048}$

$$
\mathrm{Sum}=C=\mathrm{r} 65.953
$$


That a correction of this kind is necessary becomes quite apparent if we work out the value of $C$ under the supposition that the 872 turns of wire are uniformly distributed over the average length of $43.2764 \mathrm{~cm}$. In this case we obtain $C= \pm 65.778$ or a value in error by more than I in I, Ooo.

In the above calculations no account was taken of the fact that the short coil does not fulfill the conditions leading to the simplified formula used for the evaluation of $C$, but a calculation using the more complicated formula as given by Patterson ${ }^{1}$ shows that the correction terms are so small that they will not enter in the first six significant figures of the constant $C$. The value of the correction represented by this second coil of 4.6 turns is somewhat uncertain, inasmuch as the winding is not exactly symmetrical about the mean plane and the correction turns should not be uniformly distributed over the length of the assumed uniform winding.

Professor Rosa ${ }^{2}$ has calculated the resultant magnetic field at the center of the coil by computing the effects of the I 8 sections of the winding separately and adding the results. This gives an exact value of $C$ on the assumption that the winding of each section is uniform. There can be very little uncertainty in the value of $C$ thus found, namely, I65.992, due to small variations in the winding of the separate sections.

Rosa has checked this value of $C$ by assuming a uniform distribution of the 872 turns over the cylinder and superposing on this five current sheets to represent the irregularity of winding. Two of these are negative and three are positive, the magnetic effect of the positive current sheets being in excess of the negative by 0.202 . This added to the effect of the uniform winding, I 65.778 gives I65.980, a value agreeing with that found by considering the effect of each section separately within one part in I4,000. The more exact value of $C, I 65.992$, is used in the calculations of this paper.

The five current sheets which represent the irregularity of winding are as follows:

(I) over the first 5 sections or 250 turns, carrying a current in the negative direction of I.I24 (assuming unit current in the wire) and hence equivalent to - I.I24 turns, $A B$ of Fig. I, 50 turns equal to $24.926 \mathrm{~mm}$

${ }^{1}$ Patterson, Physical Review, 20, 309; 1905.

${ }^{2}$ See his paper in this Bulletin. 
(2) over four sections (250-450 turns) carrying a current of 0.890 , in the positive direction, $C D$ of Fig. I, 50 turns equal to $24.704 \mathrm{~mm}$;

(3) over three sections (450-60o turns) carrying a current of I.292, in the positive direction, $E F$ of Fig. I, 50 turns equal to $24.60 \mathrm{Imm}$;

(4) over two sections (600-700 turns) carrying a current of o.II9, in the positive direction, $G H$ of Fig I, 50 turns equal to $24.785 \mathrm{~mm}$;

(5) over the last three sections (700-872 turns) carrying a current of I.I77, in the negative direction, IJ of Fig. I, 50 turns equal to $24.985 \mathrm{~mm}$.

Thus the two negative current sheets were together equivalent to -2.3 O turns and the three positive current sheets were equivalent to +2.3 or turns. The magnetic effect of the first is -0.340 , of the second is +0.542 , the difference being +0.202 to be added to the value due to the assumed uniform winding, as stated above. The only other irregularity of winding, besides the nonuniformity, is the slight displacement of four wires, two on each side of the hole through which the suspension for the movable coil passes. In our dynamometer this hole was only $3 \mathrm{~mm}$ wide and $8 \mathrm{~mm}$ long in the direction of the winding. It was necessary to place the wires which would otherwise have passed over it on top of the adjacent wires for a distance of about two centimeters. A very thin hard rubber lining of the hole projecting two millimeters above it allows the winding to extend close to it. The effect of this displacement upon the magnetic field strength at the center is entirely negligible.

\section{THE MOVABLE COILS.}

In order to increase the accuracy of the result it was decided to use for these determinations two movable coils of different dimensions. The frames for both consisted of porcelain cylinders from the Königliche Porzellan Manufactur at Berlin, accurately ground in the instrument shop of the Bureau. Their average diameters were carefully measured by a Zeiss vertical comparator having a calibrated scale, and by means of a newly constructed end comparator. The values obtained by the two instruments were in sufficient agreement. The method employed to locate the exact position of the diameters was the same as described under the measurements of the stationary coil; 42 diameters on the larger cylinder were measured, 36 on the smaller. As before three independent sets of readings were taken 
TABLE V.

Diameters of the Larger Coil: $t=23: 8$.

\begin{tabular}{|c|c|c|c|c|c|c|}
\hline $\begin{array}{l}\text { Number of } \\
\text { Circle }\end{array}$ & 。 & I & 2 & 3 & 4 & 5 \\
\hline 0 & $99.3267 \mathrm{~mm}$ & 99.3303 & 99.3277 & 99.3282 & 99.3273 & 99.3293 \\
\hline I & .3358 & .3322 & .3326 & .3305 & .3307 & .3328 \\
\hline II & .3377 & .3373 & .3342 & .3326 & .3320 & .3369 \\
\hline III & .3393 & .3365 & .3337 & .3305 & .3340 & .3363 \\
\hline IV & .3372 & .3368 & .3322 & .3328 & .3340 & .3390 \\
\hline $\mathrm{v}$ & .3381 & .3332 & .3317 & .3306 & .3358 & .3370 \\
\hline VI & .3319 & .3292 & .3234 & .3262 & .3295 & .3354 \\
\hline
\end{tabular}

by as many observers whose values for the average diameter agreed within $0.002 \mathrm{~mm}$. In reducing the diameter to a temperature of $25^{\circ}$ the temperature coefficient of Berlin porcelain was taken as 0.000004 .

\section{TABLE VI.}

Diameters of the Smaller Coil: $t=23{ }^{\circ}$.

\begin{tabular}{|c|c|c|c|c|c|c|}
\hline $\begin{array}{l}\text { Number of } \\
\text { Circle }\end{array}$ & o & I & 2 & 3 & 4 & 5 \\
\hline 0 & $75.2203 \mathrm{~mm}$ & 75.2172 & 75.2005 & 75.2169 & 75.2213 & 75.2270 \\
\hline I & .2217 & .2130 & .2129 & .2145 & .2220 & .2235 \\
\hline II & .2184 & .2121 & .2165 & .2170 & .2196 & .2234 \\
\hline III & .2175 & .2118 & .2128 & .2143 & .2197 & .2197 \\
\hline IV & .2128 & .2111 & .2189 & .2158 & .2177 & .2198 \\
\hline $\mathrm{V}$ & .2076 & .2007 & .2027 & .2071 & .2128 & .2104 \\
\hline
\end{tabular}

Tables V, VI, and VII show that both cylinders were quite accurately ground, the largest difference of any reading from the mean amounting in the larger one to I in ro,ooo, and in the smaller to I in 4,000 . The variation is mainly due to the fact that the ends are somewhat rounded off, i. e., the diameter is smaller, where in the complete coil no wire was wound. Taking the average for the different circles it is seen that the maximum variation from the mean is in the larger coil only $0.006 \mathrm{~mm}$, and in the smaller $0.008 \mathrm{~mm}$. Here also all but the outer circles agree within $0.002 \mathrm{~mm}$. 
TABLE VII.

Average Diameters at $25^{\circ} \mathrm{C}$.

\begin{tabular}{|c|c|c|}
\hline Circle & Larger Coil & Smaller Coil \\
\cline { 1 - 2 } O & $99.3288 \mathrm{~mm}$ & $75.2176 \mathrm{~mm}$ \\
I & .3329 & .2183 \\
II & .3356 & .2182 \\
III & .3355 & .2164 \\
IV & .3359 & .2164 \\
V & .3349 & .2073 \\
VI & .3298 & \\
\hline Average & 99.3333 & 75.2157 \\
\hline
\end{tabular}

The cylinders were then carefully wound with bare copper ribbon $0.375 \mathrm{~mm}$ thick, a space of about $0.6 \mathrm{~mm}$ being left between consecutive turns. Measurement of the diameters after winding showed that the ribbon had become thinner during the winding by 0.008 $\mathrm{mm}$ and $0.0053 \mathrm{~mm}$, respectively, due to the tension under which it was put on. The total average for the effective diameter of the cylinders, i. e., the diameter of the porcelain cylinder, plus one thickness of wire, was found to be at $25^{\circ}$,

For the larger cylinder . . 99.702 $\mathrm{mm}$.

For the smaller cylinder . . $75.5^{8} 54 \mathrm{~mm}$.

The length of the movable coil does not enter explicitly into the calculation. The number of turns were:

$$
\begin{aligned}
& \text { Larger cylinder, } n=109 . \\
& \text { Smaller cylinder, } n=83 .
\end{aligned}
$$

The area of the movable coil multiplied by the number of turns, i. e., the effective area of the coil is expressed by

$$
A=\pi r^{2} n, \text { where } r \text { is the radius of the coil, }
$$

and, calculated from the above data

For the larger coil $A=8509.9 \mathrm{~cm}^{2}$, and

For the smaller coil $A=3724.3 \mathrm{~cm}^{2}$.

Finally three coats of shellac were applied. 


\section{ELECTRODYNAMOMETER COMPLETE.}

In the construction of the electrodynamometer as a whole (see Fig. 2) care was taken to avoid any additional field which might produce a torsional moment upon the movable coil. The terminal binding posts of the two wires on either end of the stationary coil were placed in the same straight line parallel to the axis. They were fastened to a hard rubber block screwed into the plaster of Paris by means of brass screws. The wires were continued to the straight line and then bent at right angles, thus leading to the binding posts. They were held permanently in this position by the hard rubber blocks. Since in all experiments the current was sent through the two stationary wires in series, the two inner binding posts were connected by a straight wire. The current on leaving the second stationary coil was carried along another straight wire parallel to the axis back to the leading-in wire, where the two were twisted together until they reached at a distance of about 60 centimeters a small commutator. One of the leads was connected to one of the mercury cups of the commutator, while the other continued to the battery. The two wires leading to the movable coil started from two of the mercury cups and were twisted until they reached the mercury cups of the movable coil to be described presently. The fourth mercury cup connected with the battery circuit. By means of this commutator the current in the movable coil could be reversed while the direction in the stationary coil remained the same. By means of another commutator, several meters distant, the current through the whole instrument could be-reversed. This gives four possible combinations for the direction of the current in the instrument. In the battery circuit was inserted the standard resistance from the terminals of which two potential wires led to the potentiometer. The latter apparatus could be connected either to the resistance or to the standard cells whose emf. was to be measured. In order to be able to bring the movable coil to rest rapidly the instrument was shunted by a circuit containing a dry cell and a high resistance. By judicious working of the key in this circuit the amplitude of the vibration could in a very short time be reduced to a couple of millimeters on the scale. The connection with the movable coil was made by means of two mercury cups arranged one below the other. The current was carried to the upper 


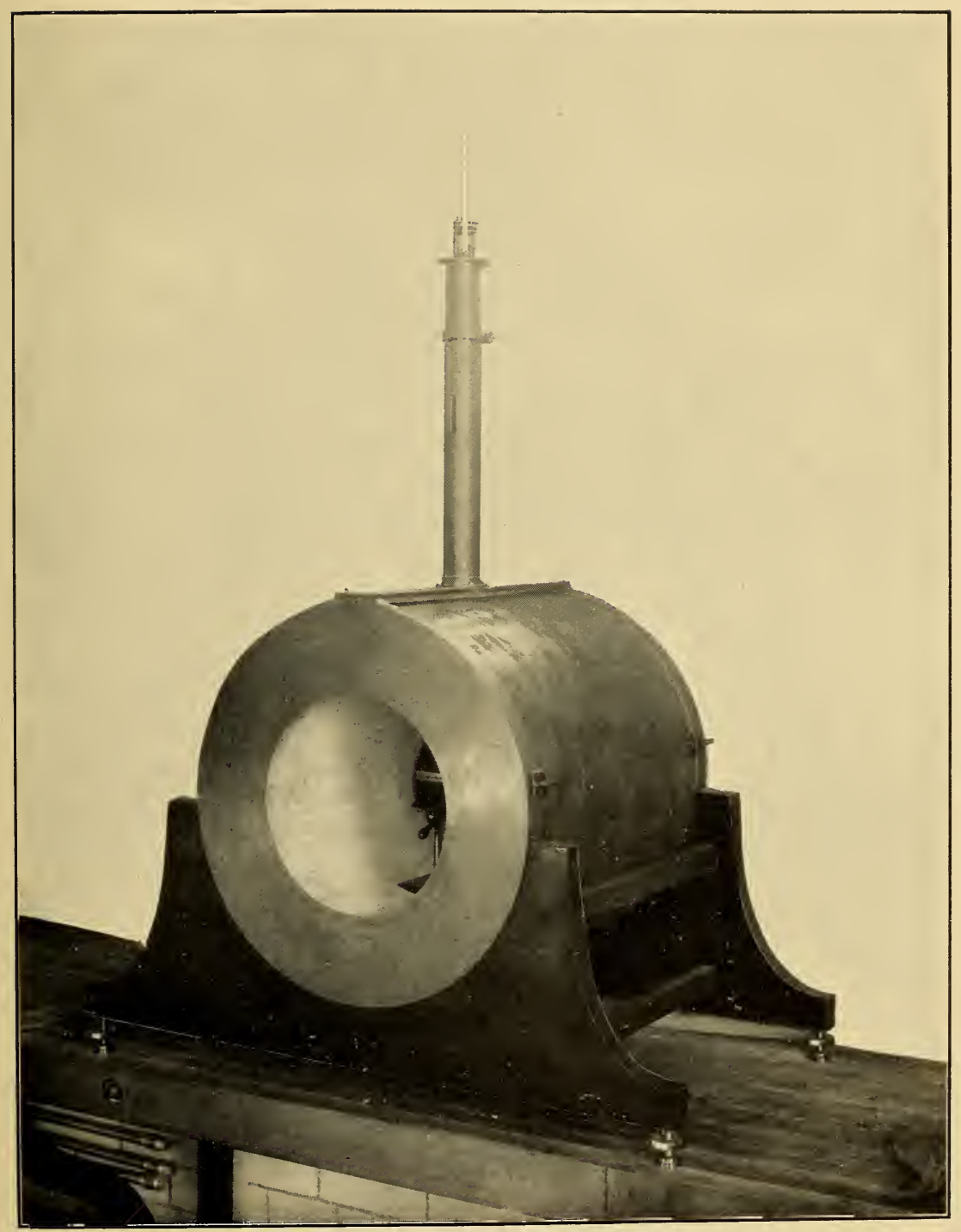

Fig. 2.-Electrodynamometer Complete. 


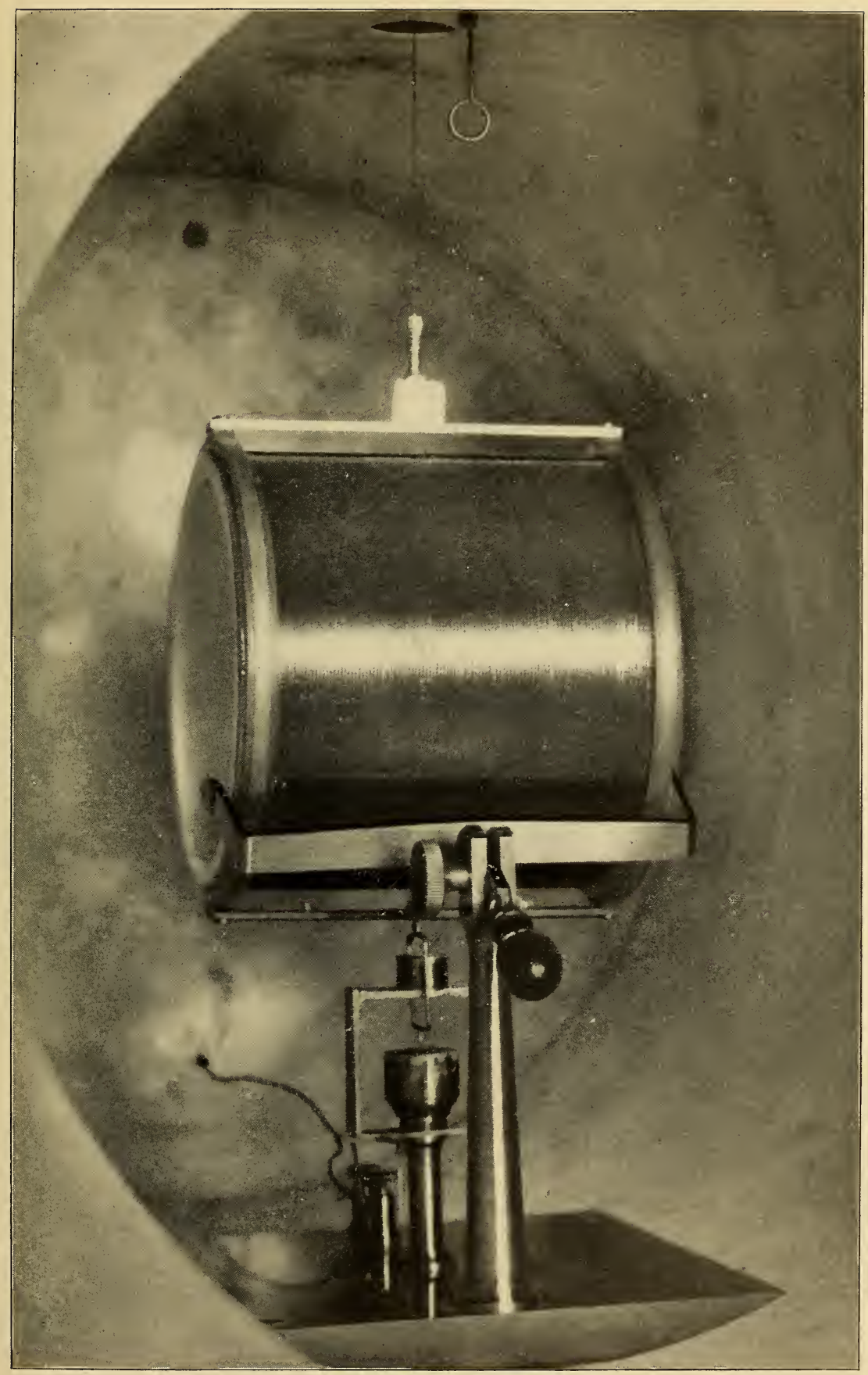

Fig. 3.-Mercury Cup Connections for Movable Coils. 
cup through a tube surrounding the conductor leading to the lower cup. A little below the latter the tube divided, forming a fork (see Fig. 3); the upper cup was carried by a bridge which closely fitted the two prongs of the fork, but could be removed to allow the introduction of the similar loop of the movable coil.

The ends of the wire of the movable coil were held in position by narrow rings of fiber which closely fitted the porcelain cylinder and carried on the lower side a thin strip of wood along which the wires were led back to the center, one being bent at right angles, the vertical part ending in a fine platinum wire dipping into the upper mercury cup, the other forming a fork extending into a vertical loop, which latter carried the platinum wire for the lower cup. In this way dissymmetry of the circuit was avoided as much as possible. The fiber rings also served to hold the small aluminium plate on top for the connection with the suspending wire. In order to limit the motion of the movable coil to a small arc and to prevent its turning beyond its position of stable equilibrium ${ }^{1}$ a fork was used having a width between the prongs only $3 \mathrm{~mm}$ larger than the length of the coil. This greatly increased the rapidity with which a determination could be made.

The suspension was supported from the top plate, capable of rotation, of a long brass tube standing on a plate of the same metal, the latter resting on the large caps which closed the plaster of Paris cylinder on either side. The whole instrument was supported by a mahogany cradle on leveling screws. The temperature was read by means of three thermometers, one inserted in the top of the brass tube, one at the bottom and read through a window in the tube, and one in the interior of the stationary coil.

It is of importance that the centers of the two coils should be coincident. For this purpose small aluminium plates with circular projections of the same diameter as the coils were slipped over the open ends of the movable coil. These plates were perforated at their centers; the straight line defined by these holes is the axis. The cap entirely closing the back of the stationary cylinder contained a vertical slit with a crosswire at the center and the circular door in front had a small hole at the center. By rotating, raising,

\footnotetext{
${ }^{1}$ Patterson and Guthe, 1. c., p. 268.
} 
or lowering the movable coil, and finally tilting it by means of a weight placed inside of the porcelain cylinder, the latter could without much trouble be centered very accurately. The cross plates on the movable cylinder were then removed and the torsion head rotated by 90 degrees. After this the apparatus was ready for a determination.

\section{MEASUREMENT OF ANGLE OF ROTATION.}

To insure a rotation of very nearly 90 degrees and the accurate determination of this angle, the following scheme was employed: On the movable and accurately fitted top of the brass tube of the electrodynamometer a small table was placed which could be leveled
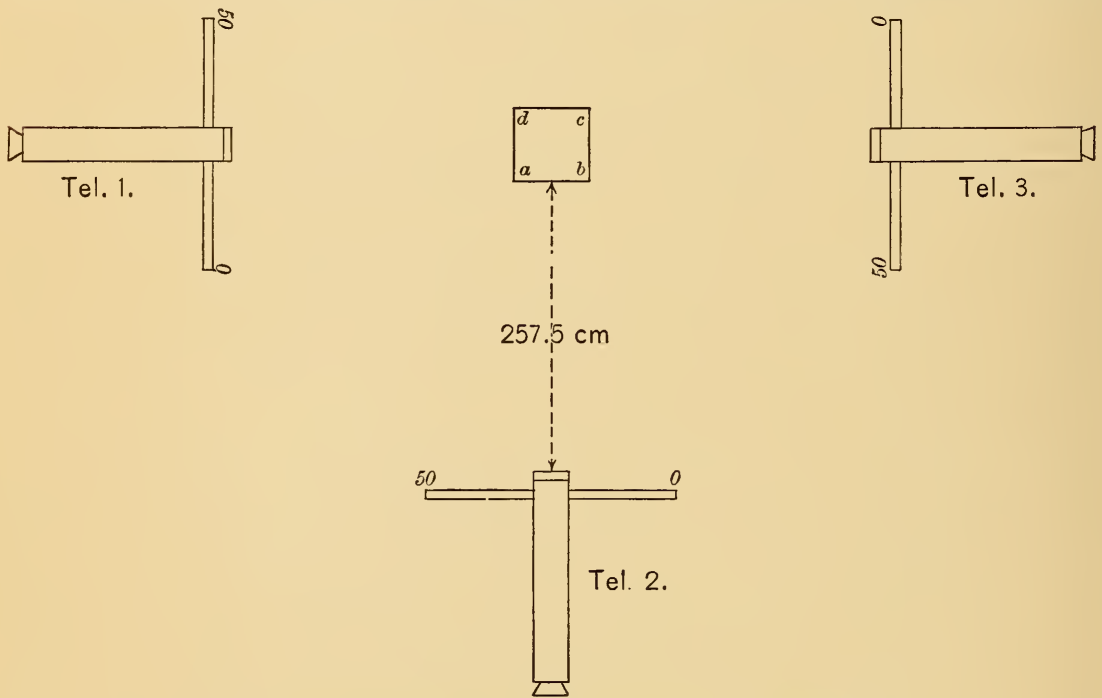

Fig. 4.-Arrangement for Measuring Angles of Glass Cube.

by three adjusting screws and which carried a glass cube with silvered sides. Opposite three sides and at a distance of $257.5 \mathrm{~cm}$ from the center of rotation, three telescopes and scales were set up at the same level as the mirrors (see Fig. 4): As reference point, the central scale mark 22.5 of the middle telescope, telescope 2, was chosen. The cubical mirror was carefully leveled so that on rotation the image of the scale always appeared at the same level in the field of the telescope, and then the readings in the telescopes were taken with each of the four faces toward telescope 2. The angles of the cube were marked $a, b, c, d$. 
TABLE VIII.

Calibration of Glass Cube.

\begin{tabular}{|c|c|c|c|}
\hline \multirow{2}{*}{ Position of Cube } & \multicolumn{3}{|c|}{ Reading in } \\
\cline { 2 - 2 } & Tel. I & Tel. 2 & Tel. 3 \\
\cline { 2 - 2 } d c & 24.745 & 22.5 & 24.75 \\
a b & & & \\
a d & 24.38 & 22.5 & 24.715 \\
b c & & & \\
b a & 24.445 & 22.5 & 25.16 \\
c d & & & \\
c b & 24.02 & 22.5 & 24.415 \\
d a & & & \\
\hline
\end{tabular}

From this follows that the reading of telescope $\mathrm{I}$ from a mirror at right angles to the one pointing toward 2 would have been 24.40 and the reading of telescope $3,24.76$, a smaller reading in the latter denoting a larger angle. The corrections for the angles in terms of scale parts are given in the following table:

\section{TABLE IX.}

Correction in Scale Parts.

\begin{tabular}{|c|c|c|c|}
\cline { 1 - 2 } Angle & Tel. I & Tel. 3 & Average \\
\cline { 1 - 2 } \cline { 1 - 2 } $\mathrm{a}$ & 0.345 & 0.345 & 0.345 \\
$\mathrm{~b}$ & -0.02 & 0.01 & -0.005 \\
$\mathrm{c}$ & 0.045 & 0.045 & 0.045 \\
$\mathrm{~d}$ & -0.38 & -0.40 & -0.39 \\
\hline
\end{tabular}

Calculating the values of the angles in degrees we obtain

Angle $a$ equals 90.0382 degrees.

$$
\begin{array}{ll}
b & 89.9994 \\
c & 90.0050 \\
d & 89.9566
\end{array}
$$

Angles $b$ and $c$ being so close to 90 degrees, they were used in all the following experiments. 


\section{MAGNETIC TESTS.}

Before deciding on the materials to be used in the construction of the electrodynamometer it was necessary to test their magnetic qualities. For this purpose two induction coils were constructed which allowed the insertion of a block of the material to be tested inside of the primary. The primaries consisted of Ioo turns of No. I4 B. \& S. wire and the secondaries of 2,000 turns of fine wire. The primaries were connected in series and the secondaries in series with a ballistic galvanometer so that the electromotive forces induced in them due to the making or breaking of the primary current were opposed to each other. The frames of the secondaries could be slightly displaced relatively to the primary by means of adjusting screws and the differential effect, as shown by the galvanometer, reduced to zero. After two more turns had been added to one of the secondaries a reversal of Io amperes in the primaries produced a deflection of $40 \mathrm{~mm}$ of the galvanometer. A deflection of I millimeter corresponds therefore to a change in the number of lines of force equal to I in 40,000. A block of plaster of Paris, having a square cross section of $100 \mathrm{~cm}^{2}$ and a length of $\mathrm{I} 5 \mathrm{~cm}$ and snugly fitting inside of the primaries was made at the same time and of the same material as the frame for the stationary coil. A similar block of marble made of the same material as two cylinders which were intended for future work was also tested. Neither material when introduced in the primary showed an effect of more than $0.25 \mathrm{~mm}$, if any, so the number of lines of force was not changed by more than I in IOO, ooo by substituting it for air. The porcelain cylinders gave the same negative result.

Fiber, brass, and aluminum, used in small quantities in the construction of the instrument, show strong magnetic effects when hung on a silk fiber near the pole of an electromagnet, but their permeability does not differ from I by more than o.ooor. In the small quantities in which these materials were made use of they could not possibly influence the result appreciably.

There was, however, one magnetic effect that had to be taken into account, i. e., that of the iron brackets supporting the wooden wall table on which the electrodynamometer was placed. The magnitude of this effect was determined as follows: A current producing a deflection of the movable coil of 90 degrees was kept constant 
during the test. The readings on the movable coil were taken repeatedly with and without the addition of another bracket of the same size and material in the same relative position to the dynamometer as each of the stationary brackets. It was found that only the nearest one of the latter affected the current. When the movable bracket was placed in position the deflection increased by 3 millimeters, which corresponds to an increase of the effect of the square of the current of $I$ in 2,700 or of the first power of the current equal to $I$ in 5,400 . This effect will therefore be taken into account in the calculation of the final result.

\section{SUSPENSION.}

A great deal of time was spent in the attempt to find a suspension for the movable coil which would show the smallest elastic aftereffect and at the same time not change its elastic properties in course of time. The attempt has been only partially successful.

The elastic after-effect was tested in a specially constructed apparatus, practically a small electrodynamometer, whose movable coil could be brought to rest in a short time, usually a fraction of a minute. After the original zero point had been determined, a twist of 180 or 360 degrees was given to the torsion head, and after a number of minutes, varying in the different experiments between one and five, the torsion head was turned back and the new resting point of the coil and its change in course of time observed. The torsion head carried also a mirror which was observed by telescope and scale so that correction might be made for failure to bring it back to exactly the same position as at the start. It is unnecessary to relate here the large number of experiments made with different materials, some of which were treated in different ways. It suffices to say that I experimented first with substances which are known to have small elastic after-effect, namely, fused quartz, steel, platinumiridium, and carbon. While it is true that the after-effect in all of them is small (though by no means negligible) when used in sizes sufficiently large to be able to carry the movable coil they were found to be entirely unsuited for the present purpose; when tested for their coefficient of torsional elasticity they showed considerable variation of the time of vibration under a constant stress on successive days. The only materials which at first were thought to be 
suitable were straight steel wires which Dr. Weston kindly sent me. These wires, after hardening and annealing at a dull blue heat, seemed very satisfactory, but although the time of vibration seemed fairly constant with a given load while it remained on the wire, it changed considerably, when the load was removed and later attached again. Professor Patterson and I had been using a phosphor bronze suspension which seemed to have the desirable qualities, though we had not made exhaustive tests in this connection; our experience at that time did not show any such irregularities as were the regular occurrence in the early part of this investigation. My first experiments on phosphor bronze ribbons of various sizes were very unsatisfactory, on account of their large elastic after-effect. Fortunately through the kindness of Mr. H. B. Brooks I obtained a piece of phosphor bronze wire twelve years old, and this proved to be superior to all other material tried. The after-effect was small, and while it changed its elastic properties in course of time it remained constant enough for a week, so that with the proper precautions the experiments could be performed before a change took place. After the torsion head had been kept twisted r8o degrees for 2 minutes, the displacement of the zero point amounted to only 3 or $4 \mathrm{~mm}$ on a scale $\mathrm{I} / 2$ meters from the mirror.

The modulus of torsion of the suspension, i. e., the torsional moment of the wire for unit angle, was determined by vibrating a cylinder of known moment of inertia and calculating from the formula

$$
\tau=\frac{4 \pi^{2} K}{T^{2}}
$$

where $K$ is the moment of inertia of the vibrating mass and $T$ the period of a complete vibration.

The ends of the wire were soldered into brass cylinders, the smaller of which was a pin, by means of which the wire was clamped to the torsion head. The larger cylinder, consisting of Tobin bronze, which seems to be of more uniform density than ordinary brass, formed a part of the vibrating system. It may be considered as two coaxial cylinders, the upper longer one of uniform diameter and the lower a flat circular plate of slightly larger diameter. To the lower end a small mirror was fastened. In the electrodyna- 
mometer the wire was inverted, the larger cylinder passing through the torsion head while the movable coil was fastened to the small pin. Thus the length of the wire remained the same as in the torsional experiments.

Over the Tobin bronze cylinder larger hollow cylinders of different dimensions and of the same naterial could be slipped, the holes in these being fitted as exactly as possible to the narrower part of the former. These cylinders were very accurately turned. Their dimensions were measured by means of an end comparator and their

TABLE X.

Tobin Bronze Cylinders.

\begin{tabular}{c|c|c|c}
\hline \multicolumn{3}{c}{ Hollow Cylinders. Temp. 25 } \\
\hline Cylinder & Mean Diameter & Mean Height & Mass (incl. gold) $\mathbf{M}_{\mathbf{I}}$ \\
\hline A & $44.2816 \mathrm{~mm}$ & $38.1925 \mathrm{~mm}$ & 483.9432 grams \\
C & 59.6630 & 20.8442 & 483.9968 \\
D & 57.2224 & 15.8071 & 337.2682 \\
E & 49.8946 & 20.8864 & 337.6404 \\
\hline
\end{tabular}

Inner Cylinder. Temp. $25^{\circ}$

\begin{tabular}{c|c|c|c|c}
\hline $\begin{array}{c}\text { Mean Total Length } \\
\text { L+I }\end{array}$ & $\begin{array}{c}\text { Mean Diame- } \\
\text { ter, d }\end{array}$ & $\begin{array}{c}\text { Mean Height of } \\
\text { Head, } \mathrm{I}\end{array}$ & $\begin{array}{c}\text { Mean Diameter of } \\
\text { Head, D }\end{array}$ & Mass $\mathbf{M}_{2}$ \\
$34.470 \mathrm{~mm}$ & $6.049 \mathrm{~mm}$ & $3.993 \mathrm{~mm}$ & $7.995 \mathrm{~mm}$ & 9.0500 grams \\
\hline
\end{tabular}

Glass Mirror.

\begin{tabular}{c|c|c}
\hline Length, a & Thickness, b & Mass $\mathbf{M}_{3}$ \\
\cline { 2 - 3 } $14.043 \mathrm{~mm}$ & $0.3376 \mathrm{~mm}$ & 1.865 grams \\
\hline
\end{tabular}

masses accurately determined. For these determinations also I am indebted to the division of Weights and Measures. In order to avoid changes in weight due to oxidation the cylinders were gold plated, the amount of gold deposited being only a few milligrams and having, as calculation showed,' a negligible effect upon the moment of inertia determined under the supposition that the cylinders consisted of bronze of uniform density. Two pairs of cylinders 
were used in the final experiments, those of each pair having the same mass, but different dimensions. One of them, A, fulfilled the condition that the ratio of length to radius should be as $\sqrt{3}: \mathrm{I}$, in which case a slight error in the axis of rotation produces a minimum error in the moment of inertia. ${ }^{1}$ The other cylinders were flatter and had a correspondingly larger diameter. Two cylinders were made for each set in order to test whether the moment of inertia of such small cylinders could be calculated with sufficient accuracy. Two sets of different mass were made because the masses of the movable coils differed considerably and it was found that the modulus of torsion depended upon the tension of the wire. It was, in fact, necessary to make the weights of the movable coils equal to those of the cylinders with which the torsional moments were determined. This was done by adjusting the mass of the small metal rod, which was placed inside the porcelain cylinder and served for the centering of the axis, until the total weight of the movable coil was equal to that of the corresponding bronze cylinders.

Other Tobin bronze cylinders of different mass were used, but since they do not directly concern the determination under discussion, the results obtained with them will be omitted.

The moment of inertia of the hollow cylinders was calculated from the formula

$$
K_{1}=M_{1} \frac{R^{2}+r^{2}}{2}
$$

that of the inner cylinder from

$$
K_{2}=\frac{M_{2}}{8}\left(\frac{L d^{4}+l D^{4}}{L d^{2}+l D^{2}}\right)
$$

where $L, d$, and $l, D$, are the lengths and diameters of the narrower and the wider part, respectively; and that of the mirror from

$$
K_{3}=M_{3} \frac{a^{2}+b^{2}}{12} .
$$

Table XII shows the change of the elastic coefficient in course of time. During the first experiments in July and the early part of August, it was noticed that the change was especially pronounced after the heavier cylinders had been on the wire, so after the second set in August a load heavier than any to be used in the later 
experiments was hung on the wire. This produced a large change, but had the effect of making the wire more constant. The table also shows the agreement between the torsional moments, as determined by means of the two cylinders $\mathrm{A}$ and $\mathrm{C}$. Of the last two determi-

TABLE XI.

Moments of Inertia of Cylinders at $25^{\circ}$.

\begin{tabular}{|c|c|c|c|c|}
\hline & A & c & $\mathrm{D}$ & $\mathrm{E}$ \\
\hline Moment of outer cylindes, $\mathrm{K}_{\mathrm{r}} \ldots \ldots$ & 1208.321 & 2175.730 & 1395.870 & 1066.137 \\
\hline Moment of small inner cylinder, $\mathbf{K}_{2 .-}$ & 0.471 & 0.471 & 0.471 & 0.471 \\
\hline Moment of mirror, $\mathrm{K}_{3} \ldots \ldots \ldots .$. & 0.324 & 0.324 & 0.324 & 0.324 \\
\hline Total moment, $\mathrm{K} . .$. & 1209.12 & 2176.52 & 1396.66 & 1066.93 \\
\hline
\end{tabular}

nations, made in September, the first was taken before and the second after the determination of the electromotive force of the standard cells, showing a sufficient constancy during that interval.

TABLE XII.

Modulus of Torsion of Suspension with Cylinders A and C. Temperature $25^{\circ}$.

\begin{tabular}{c|c|c|c|c}
\hline \multicolumn{1}{c|}{ Date } & Cylinder & Period & Modulus & \multirow{2}{*}{ Average } \\
\cline { 1 - 2 } July 25-26 & A & 12.4136 & 309.766 & \\
27-29 & C & 16.6556 & 309.744 & 309.755 \\
Aug. 17-18 & A & 12.4176 & 309.567 & \\
19-21 & C & 16.6602 & 309.572 & 309.569 \\
Sept. 23 & A & 12.4281 & 309.044 & \\
26 & C & 16.6752 & 309.016 & 309.030 \\
\hline
\end{tabular}

The period was determined by the well-known method of coincidences; the second clicks being given by a break-circuit chronometer, which was regularly compared with the standard Riefler clock. The corrections of the chronometer were negligible. The temperature coefficient is rather large for the phosphor bronze, so the readings of two or three thermometers placed along the wire were carefully noted every fifteen minutes. The apparatus in which the swinging system was suspended was protected from air currents, but it was 
found unnecessary to swing the cylinders in vacuo, since the friction of the air did not produce an appreciable effect on the period. Experiment showed that the periods in air and in vacuo were the same within a few ten-thousandths of a second. The periods were always determined by at least two observers and their results agreed usually within 0.0002 second.

The agreement between the torsional moduli, as calculated from the periods with cylinders $\mathrm{D}$ and $\mathrm{E}$, was not nearly as satisfactory, as will be seen from Table XIII.

TABLE XIII.

Modulus of Torsion of Suspension with Cylinders D and E. Temperature $25^{\circ}$.

\begin{tabular}{c|c|c|c|c}
\multicolumn{1}{c|}{ Date } & Cylinder & Period & Modulus & Average \\
\cline { 1 - 3 } July $29-31$ & D & 13.3488 & 309.435 & \\
Aug. $1-2$ & E & 11.6692 & 309.325 & 309.380 \\
$21-23$ & E & 11.6742 & 309.059 & \\
$24-27$ & D & 13.3546 & 309.166 & 309.112 \\
Sept. 18 & E & 11.6809 & 308.634 & 308.688 \\
\hline
\end{tabular}

Cylinder $\mathrm{D}$ gives a torsional modulus higher by 0.108 than $\mathrm{E}$. At first it seemed best to throw out the value obtained with $D$, on account of the disk-like shape of the cylinder and the consequent liability to have too small a moment of inertia if the axis is slightly tilted, and therefore only $\mathrm{E}$ was used at the time of the electrical determination. This seems, however, to be an unjust discrimination against $\mathrm{D}$, especially since no such tilting was noticeable to the eye. I decided therefore to use in the later calculations the mean value, i. e., one 0.054 higher than the value given by cylinder $\mathrm{E}$. As can be seen from a later formula, an error of that amount would produce in the final result for the current an error a little smaller than $\mathrm{I}$ in ro,ooo.

The temperature coefficient for the vibration periods was determined a great many times, and was found to be o.0oor95. This value agrees very well with that found by Professor Patterson and myself. The periods for a given cylinder plotted as a function of the temperature give a straight line. In the evaluation of the tem- 
perature coefficient of the modulus of torsion we have, however, to take into account the expansion of the cylinders, whose coefficient was assumed to be 0.000018 . Since the modulus of torsion is pro-

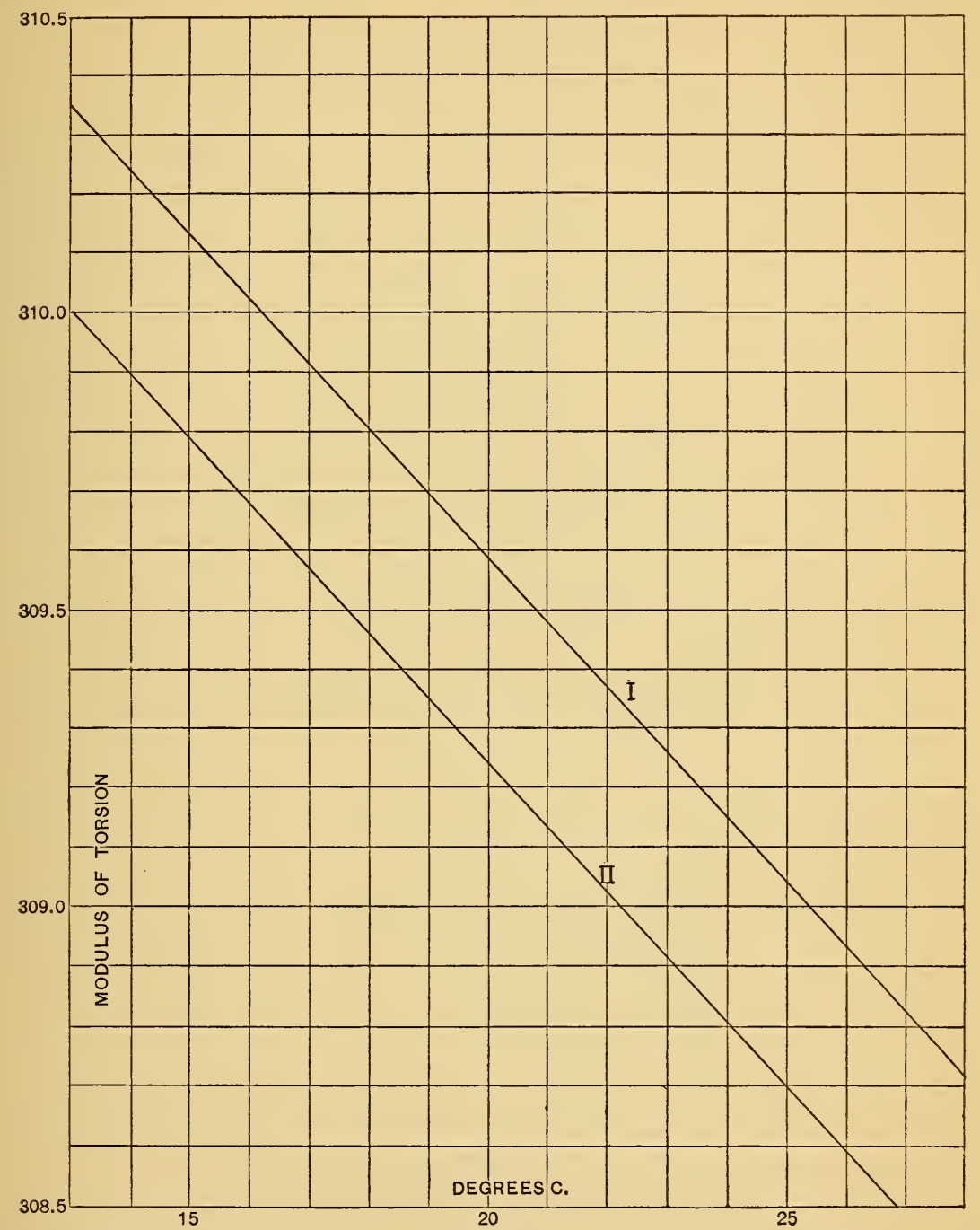

Fig. 5.-Modulus of Torsion of Suspension as a Function of Temperature. I, with larger coil; II. with smaller coil.

portional to the moment of inertia and inversely proportional to the square of the time of vibration, the temperature coefficient for the 
modulus of torsion becomes 0.000354 . In Fig. 5 the two moduli have been plotted as functions of the temperature, the higher curve corresponding to a load equal to the larger movable coil and the lower to that of the smaller coil.

\section{THE STANDARD CELLS.}

Professors Carhart and Hulett kindly furnished me twelve standard cells, three Clark and nine Weston (cadmium), prepared in different ways. They will be designated by the marks they bore when I received them. They had been transported carefully so as to disturb them as little as possible. All of them were of the $\mathrm{H}$ form and hermetically sealed by drawing out the upper portions of the tubes through which the materials had been introduced.

I. Cadmium Cells. $-C_{3}$. $\mathrm{Hg}_{2} \mathrm{SO}_{4}$ prepared chemically by adding dilute $\mathrm{H}_{2} \mathrm{SO}_{4}$ to $\mathrm{HgNO}_{3}$. The precipitate was washed with water until the top was quite yellow; this layer was removed and the rest made up into the paste. Kahlbaum's c. p. $\mathrm{CdSO}_{4}$ used. Amalgam I 2.5 per cent electrolytic cadmium melted with distilled mercury. Set up November 2I, 1903, by Hulett; emf. apparently constant since January, I904.

$E_{2}$ and $E_{5} . \mathrm{Hg}_{2} \mathrm{SO}_{4}$ prepared electrolytically, and cells set up January, I904, by Carhart. In $E_{5}$ the $\mathrm{Hg}_{2} \mathrm{SO}_{4}$ had worked in between the mercury and the platinum wire, and no results could be obtained with it.

$F_{8}$ and $F_{9} . \quad \mathrm{Hg}_{2} \mathrm{SO}_{4}$ prepared electrolytically and washed with $\mathrm{CdSO}_{4}$ solution. The acid used in the preparation was of greater than molecular concentration, a condition necessary to avoid hydrolysis. ${ }^{1}$ The $\mathrm{CdSO}_{4}$ was recrystallized and the amalgam made electrolytically. Set up by Carhart and Hulett February I5, I904. $K_{6}$. The electrolytic $\mathrm{Hg}_{2} \mathrm{SO}_{4}$ was washed with alcohol and ether. Set up by Hulett July 9, I904.

$K_{10}$. The $\mathrm{Hg}_{2} \mathrm{SO}_{4}$ was prepared chemically by adding $\mathrm{HgNO}_{3}$ to $\mathrm{H}_{2} \mathrm{SO}_{4}$ of concentration I to 6 . Set up July 9, I904.

$O_{1}$ and $O_{2}$. Hulett's electrolytic $\mathrm{Hg}_{2} \mathrm{SO}_{4}(\mathrm{No} . A$ ) washed with $\mathrm{CdSO}_{4}$ solution. Set up by Mr. Trout February II, I905.

2. Clark Cells. $-R_{1}, R_{2}$, and $R_{4}$. The mercurous sulphate was prepared electrolytically and washed with zinc sulphate solution. The 
zinc sulphate was twice recrystallized from Merck's c. p. salt; Io per cent amalgam used for negative electrode. Set up by Hulett May 3, I905. It should be stated that the electrolytic mercurous sulphate in the different series was from different batches, prepared at different times: for the E series by Carhart, for the rest by Hulett. The cells were placed in a thermostat of the Ostwald type, the cells being immersed in an oil bath and their temperature kept constant within o.OI degree. I am much indebted to Professor Hulett for valuable help in the construction of the thermostat and the first few comparisons of the cells, which showed that the cells that he kindly left with me had not changed during transport with respect to the total average of all his cells, which were also measured at the same time.

Besides these standard cells I had at my disposal six Weston cells (unsaturated), which Dr. W. A. Noyes had a short time before brought from Europe and for which we received Reichsanstalt certificates. These cells, with the exception of one, showed no variation in their relative emf., and might therefore be used with a fair degree of accuracy for a direct comparison with the Reichsanstalt values. In fact, in making my comparisons I selected one of them (No. 8I3) as reference standard as having an emf. of r.or 882 volts at $2 \mathrm{I}^{\circ}$, and a temperature coefficient of $-0.0000 \mathrm{I}$. It should be

TABLE XIV.

Comparison of Standard Cells. Weston Cell No. 813 assumed to have an emf. at $21^{\circ}$ of 1,01882 Volts.

\begin{tabular}{l|r|r|r|r}
\hline Cel1 & Sept. II & Sept. I7 & Sept. 24 & Sept. 26 \\
\cline { 2 - 3 } \cline { 5 - 5 } $\mathbf{F}_{8}$ & $1.01824 \mathrm{v}$. & 1.01825 & 1.01825 & 1.01825 \\
$\mathbf{F}_{9}$ & 26 & 26 & 26 & 25 \\
$\mathbf{E}_{2}$ & 28 & 29 & 29 & 30 \\
$\mathrm{~K}_{6}$ & 31 & 31 & 23 & 28 \\
$\mathrm{~K}_{10}$ & 31 & 31 & 30 & 32 \\
$0_{1}$ & 31 & 32 & 31 & 32 \\
$0_{2}$ & 30 & 31 & 31 & 31 \\
$\mathrm{C}_{3}$ & 54 & 55 & 54 & 55 \\
$\mathrm{R}_{1}$ & 1.42034 & 1.42038 & 1.42036 & 1.42037 \\
$\mathrm{R}_{2}$ & 35 & 38 & 36 & 37 \\
$\mathrm{R}_{4}$ & 35 & 38 & 36 & 38 \\
\hline
\end{tabular}


kept in mind that the Reichsanstalt always refers to the emf. of the Clark cell as 1.4328 volts. Table XIV gives the results of the comparisons, beginning with September II, I905. The temperature of the earlier experiments was $0.10^{\circ}$ too high. After the thermometer (Golaz No. 3583) reading to $0.02^{\circ}$ had been compared with the primary standards, the temperature of the thermostat was adjusted to $25^{\circ}$ within $0.01^{\circ}$ and kept there for the rest of the time. The comparisons were made with a calibrated Wolff potentiometer.

As will be seen, the cadmium cells with electrolytic mercurous sulphate form two distinct series, the $F$ series having an emf. about 0.00006 volt lower than the rest, probably due to the fact that in the former the acid in which the mercurous sulphate was formed had a concentration larger than normal. It is rather interesting to note that cell $K_{10}$, prepared chemically by adding the mercurous nitrate to the sulphuric acid, also shows the low values of the electrolytic cells. The abnormal drop of the emf. of $K_{6}$ is probably due to an accidental short circuit. Cell $C_{3}$, prepared in the usual way, has an emf. 0.00030 volt higher than the $F$ series. Reducing to $20^{\circ}$, using the temperature coefficient found at the Reichsanstalt, ${ }^{1}$ its value would be I.or 875 volts, or 0.000 I 5 volt higher than the value given by them to the cadmium cell.

The emf. of the Clark cells reduced to $\mathrm{I} 5^{\circ}$, using the accepted temperature coefficient, would be $\mathrm{r} .43300$ volts; but it seems from Hulett's ${ }^{2}$ experiments with these cells that they have a slightly different coefficient, and assuming this the emf. would be $\mathrm{r} .43293$ volts at $15^{\circ}$, or 0.00013 volt higher than the Reichsanstalt value. Since practically the same difference had been found for the cadmium cells, prepared chemically, the conclusion seems justified that in the case of the Clark cells the electrolytic preparation of the mercurous sulphate does not produce as large a difference in the emf. as in the cadmium cells, a point which ought to be studied more carefully. The difference between the Reichsanstalt values and mine may be accounted for by a change of the Weston cells, which were newly set up, and as the account from the European Weston Electrical Company had shown changes just previous to their shipment. The low values of the Clark cells in the first com-

${ }^{1}$ Jaeger and Kahle, Zs. für Instrumentenkunde, 28, I70; I898.

${ }^{2}$ Hulett, Physical Review, 22, 48; 1906. 
parison given above are probably due to the fact that they had not adjusted themselves completely during two days to the new temperature condition.

\section{THE ELECTRICAL DETERMINATIONS. ${ }^{1}$}

After the apparatus was set up, ready for the electrical part of the experiment, the insulation resistance between the two separate windings of the stationary coil with the twisted lead wires was tested and found to be 30 megohms.

The arrangement of the apparatus is given diagrammatically in Fig. 6. From a battery $B$ of $\mathrm{I} 20$ volts the current was sent throngh the standard resistance $R$ and a rheostat $W_{1}$ capable of continuous

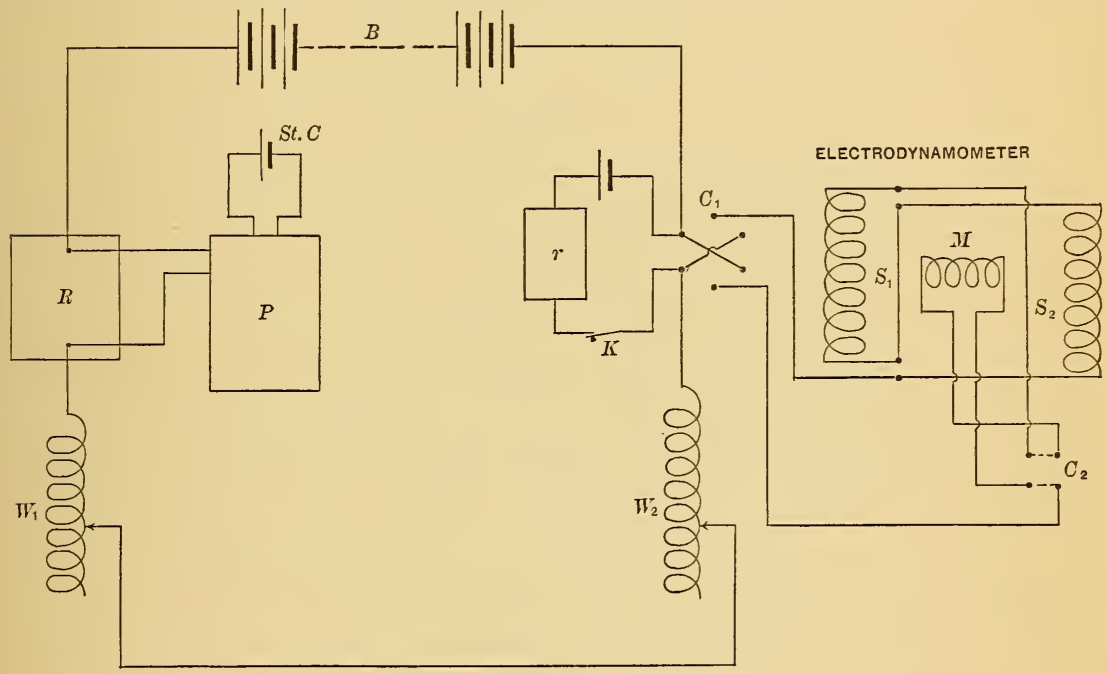

Fig. 6.-Plan of Connections.

adjustment, which could be operated by the observer stationed at the potentiometer $P$. The latter served for the comparison of the standard cells with the potential difference at the terminals of the standard resistance. From the resistance $W_{1}$ the current was led to the electrodynamometer, passing on its way through a rheostat $W_{2}$, which could be adjusted by small steps and was operated by the observer stationed at the electrodynamometer. The two commutators allowed a reversal of the current passing through the whole instrument, and for each of the directions in the stationary coil a

${ }^{1}$ I wish to express my indebtedness to Prof. C. MI. Jansky and Mr. C. A. Pierce for valuable assistance in the experimental work.

$$
\text { 24353-No. I-06-5 }
$$


reversal in the movable coil. The four possible combinations of the current were made necessary in order to eliminate (I) the effect of the earth's magnetic field and (2) the influence of the lead wires. The axis of the fixed coil was approximately parallel to the magnetic meridian. The effect of the earth's field on the torque is proportional to the first power of the current, that due to the electrodynamometer proportional to the second power. The formulæ for the torque due to $i_{1}$ and $i_{2}$ (the values of the current in the two directions, respectively), this torque being balanced by the torsion of the wire, which is the same in each case, are as follows:

or eliminating $b$

$$
\begin{aligned}
& T=a i_{1}{ }^{2}+b i_{1} \\
& T=a i_{2}{ }^{2}-b i_{2}
\end{aligned}
$$

$$
T=a i_{1} i_{2}
$$

Taking the geometrical mean of the two currents actually found will therefore eliminate the influence of the earth's field. If the lead wires have an appreciable influence, the constant $a$ consists of two parts, one, $c$, due to the effect of the two coils upon each other and the other, $d$, to the lead wires. By reversing the direction of the current through the two coils with respect to each other, and as before, finding two currents balancing the moment $T$ we obtain finally

$$
T=(c+d) i_{1} i_{2} \text { and } T=(c-d) i_{3} i_{4}
$$

Multiplying these two equations together we have

$$
T^{2}=\left(c^{2}-d^{2}\right) i_{1} i_{2} i_{3} i_{4}
$$

or $T=c \sqrt{i_{1} i_{2} i_{3} i_{4}},=c I^{2}$, where $I$ is the geomet-

rical mean of the four currents, if we neglect the factor $\sqrt{\mathrm{I}-\frac{d^{2}}{c^{2}}}$ after taking the square root. Experiments showed that $\frac{d}{c}$ was about $\frac{\mathrm{I}}{\mathrm{I} 2000}$ and hence the factor neglected differs from unity by only one in $288,000,000$. Hence, taking the geometrical mean of the four currents as the value of $I$ completely eliminates the effect of the earth's field and of the leads. In all our experiments we twisted the torsion head by an angle nearly 90 degrees and determined the cur- 
rent necessary for a balance, then calculated its value for exactly 90 degrees, i. e., the current which would hold the movable coil in its original position, if the torsion head were turned by exactly 90 degrees. The geometric mean of the four values found for the different combinations of the current was then used for further calculation. We selected 90 degrees because in this case the elastic after-effect of the wire is very small for a twist lasting, as in our experiments, only a few minutes. It was, however, taken into account, for immediately after the current was broken, the torsion head was turned back, the movable coil brought nearly to rest and then the small elongations on either side noted for several minutes. From the calculated resting points extrapolation would give us the resting point corresponding to the moment when the coil was turned back. The correction applied hardly ever amounted to more than one millimeter, which with a distance of $257.5 \mathrm{~cm}$ of the observer's telescope and scale from the mirror of the movable coil corresponds to a change of only I in 8, Ioo. Usually the correction was in the neighborhood of $0.5 \mathrm{~mm}$ or $\mathrm{I}$ in $\mathrm{r} 6,000$. The twist of the torsion head was determined by means of the silvered glass cube, described on page 50 . It was placed on top of the torsion head in such a position that the side whose adjacent angles were $b(=89.9994$ degrees $)$ and $c(=90.0050$ degrees) pointed toward the telescope and the reflection of a scale placed at the same distance from the cube as that of the lower scale from the mirror of the movable coil was observed. A turning to larger numbers meant a turning of the cube through angle $b$, in the opposite direction through angle $c$. From the original reading and that after turning, the angle of twist which was always very close to 90 degrees could be accurately calculated.

The procedure for any one of the four observations, necessary for a complete determination was as follows: The temperature was read on the three thermometers distributed along the wire and the reading of the potentiometer with the standard cell No. 8I 3 was taken. One observer was stationed at the electrodynamometer, another at the potentiometer, and an assistant was ready to turn the torsion head at a given signal. Readings were taken of the scales reflected by the glass cube and the mirror of the movable coil. Then at a noted time the torsion head was turned until the reflection from the 
next side of the cube was nearly the same as from the original. The observer at the dynamometer adjusted the rheostat $\mathrm{W}_{2}$ (see Fig. 6) until the reading of the scale reflected from the mirror of the movable coil was very nearly the same as before, using at the same time the damping device described above, and he called out to the observer at the potentiometer as soon as the coil passed through the original resting point. The assistant at the potentiometer had been following the variations in the current and at the signal given by his companion held the current constant by regulating the rheostat $\mathrm{W}_{1}$. This could be done within a few units of the last dial of the potentiometer; that is, within a few parts in Ioo,ooo. During this time the first observer read the extreme swings of the movable coil, usually three, then opened the circuit and called out to the assistant to turn the torsion head back to its original position. After this the readings of the swinging coil were taken for several minutes to allow correction for elastic after-effect. Finally the new position of the torsion head was accurately read, and the reading of the potentiometer with the standard cell repeated. It was found necessary to slightly tap the stand on which the two mercury cups leading to the movable coil were placed because it was found that without this precaution the surface tension of the mercury slightly affected the final position of the coil. Several schemes were employed to overcome this trouble but nothing was found to be as efficient as the slight tapping, which was done by a fork passing through the door of the stationary coil. The assistant who turned the torsion head thus kept the mercury agitated throughout the experiment. This shaking was responsible for the difficulty in keeping the current more constant than to the degree mentioned above, but, as we found from several unsuccessful determinations, it could not be dispensed with.

Four such observations served for the determination of the current necessary to balance the torsional moment of the wire. Since the latter was twisted in every case 90 degrees, the torsional moment due to the wire was $\frac{\pi}{2} \tau$. The strength of the field at the center of the stationary coil is

$$
H=\frac{4 \pi N}{\sqrt{D^{2}+L^{2}}} I=C I
$$


Where $N$ is the number of turns on the stationary coil, $D$ and $L$ are the diameter and length of the stationary coil, $I$ the current expressed in c. g. s. units.

The effective area of the movable coil is given by

$$
A=\pi r^{2} n,
$$

where $n$ is the number of turns, and $r$ the radius of the coil. The torsional moment produced by a current $I$ flowing through the electro-dynamometer is then

$$
T=A C I^{2}
$$

The values for $C$ and $A$ have been given above, and are

$$
\begin{aligned}
C & =165.992 \mathrm{~cm}^{-1}, \\
A \text { for the larger movable coil } & =8509.9 \mathrm{~cm}^{2}, \\
A \text { for the smaller coil } & =3724.3 \mathrm{~cm}^{2} .
\end{aligned}
$$

The value of the current expressed in c. g. s. units is therefore given by

$$
\begin{aligned}
I^{2} & =\frac{\pi \tau}{2 A C}=\frac{\mathrm{I}}{\mathrm{I} 4 \mathrm{I} 2575} \cdot \frac{\pi}{2} \cdot \tau \text { for the larger coil, } \\
& =\frac{\mathrm{I}}{6 \mathrm{I} 82 \mathrm{O} 3} \cdot \frac{\pi}{2} \cdot \tau \text { for the smaller coil. }
\end{aligned}
$$

The value for $\tau$ to be used with the larger coil was $309.030 \mathrm{gm} \mathrm{cm}^{2}$ $\mathrm{sec}^{-2}$ at $25^{\circ}$, for the smaller coil $308.688 \mathrm{gm} \mathrm{cm}^{2} \mathrm{sec}^{-2}$ at $25^{\circ}$. In each determination this value has to be corrected for temperature. Seven complete determinations were made, three with the smaller coil and four with the larger. The standard cell used as standard of comparison was the Weston cell No. 8I3. Since the electromotive forces of all the others are accurately known in terms of this, their values in absolute units can easily be calculated. In Tables $\mathrm{XV}$ and XVI a summary of these experiments is given. Under $(A)$ we find the results of the four partial observations, corrected for a torsion equal to 90 degrees, the different directions of the current being indicated by $a, b, c$, and $d$. The effect of the earth's magnetic field is quite apparent; on the other hand the effect of the leading-in wires is very small. Under $(B)$ I give a short outline of the final calculation. In the first line we find the geometrical mean of the 
four readings of the potentiometer given under $(A)$, in the third the torsional moment for unit angle of twist corrected for the temperature of the dynamometer. In the next line follows the value of the current in c. g. s. units, calculated as shown above, and corrected for the magnetic influence of the bracket, then the potential difference

\section{TABLE XV.}

Determinations with Small Movable Coil.

(A)

\begin{tabular}{c|c|c|c}
\hline \multirow{2}{*}{ Direction of Current } & \multicolumn{3}{|c}{ Reading of Potentiometer } \\
\cline { 2 - 4 } & Experiment I & Experiment 2 & Experiment 3 \\
\cline { 2 - 4 } $\mathrm{a}$ & 0.82861 & 0.82875 & 0.82844 \\
$\mathrm{~b}$ & .85145 & .85172 & .85181 \\
$\mathrm{C}$ & .82881 & .82868 & .82883 \\
$\mathrm{~d}$ & .85173 & .85176 & .85163 \\
\hline
\end{tabular}

(B)

\begin{tabular}{|c|c|c|c|}
\hline Pot. Diff. observed. & 0.84008 & 0.84017 & 0.84010 \\
\hline Temperature ........... & $25: 20$ & $25: 27$ & $25: 18$ \\
\hline Modulus of torsion ............. & 308.736 & 308.727 & 308.738 \\
\hline Current in c. g. s. units. ......... & 0.0280029 & 0.0280025 & 0.0280030 \\
\hline Pot. Diff. calculated . . . . . . . . . . . . & 0.840143 & 0.840131 & 0.840146 \\
\hline Pot. Diff. $\frac{\text { calculated }}{\text { observed }}$ & 1.00008 & 0.99995 & 1.00005 \\
\hline Emf. of Std. Cell No. $813 \ldots \ldots \ldots .$. & 1.01890 & 1.01877 & 1.01887 \\
\hline
\end{tabular}

calculated from Ohm's law. In the experiments with the smaller coil the standard resistance was $3.00020 \mathrm{ohms}$ at $25^{\circ}$, i. e., the temperature of the well stirred oil bath in which they were kept; with the larger coil the resistance was $6.0003^{8} \mathrm{ohms}$ at $23^{\circ}$. These resistances were accurately compared with the standards of the Bureau. In the remaining two lines of the tables are given the ratio between the calculated and the observed potential differences and the emf. of our reference cell Weston No. $8 \mathrm{I} 3$ at $2 \mathrm{I}^{\circ}$, as determined by the absolute measurement. 
TABLE XVI.

Determinations with Large Movable Coil.

(A)

\begin{tabular}{c|c|c|c|c}
\hline \multirow{2}{*}{ Direction of Current } & \multicolumn{4}{|c}{ Reading of Potentiometer } \\
\cline { 2 - 5 } & Experiment 4 & Experiment 5 & Experiment 6 & Experiment 7 \\
\cline { 2 - 5 } $\mathrm{a}$ & 1.08971 & 1.08971 & 1.08959 & 1.08958 \\
$\mathrm{~b}$ & 1.13573 & 1.13561 & 1.13579 & 1.13571 \\
$\mathrm{C}$ & 1.08956 & 1.08970 & 1.08966 & 1.08951 \\
$\mathrm{~d}$ & 1.13554 & 1.13546 & 1.13536 & 1.13579 \\
\hline
\end{tabular}

(B)

\begin{tabular}{l|c|c|c|c}
\hline Pot. Diff. observed..... & 1.11240 & 1.11238 & 1.11237 & 1.11241 \\
Temperature ........ & 23.44 & 23.62 & 23.47 & 23.60 \\
Modulus of torsion .... & 309.200 & 309.180 & 309.195 & 309.182 \\
Current in c. g. s. units. & 0.0185394 & 0.0185388 & 0.0185393 & 0.0185388 \\
Pot. Diff. calculated... & 1.11243 & 1.11240 & 1.11242 & 1.11240 \\
Pot. Diff. calculated & 1.00003 & 1.00002 & 1.00004 & 1.00001 \\
Emf... of Std. Cell No.813 & 1.01885 & 1.01884 & 1.01886 & 1.01883 \\
\hline
\end{tabular}

Taking the average of the seven determinations of the emf. of Weston cell No. $8 \mathrm{I} 3$ at $2 \mathrm{I}^{\circ}$, giving the first three only half the weight of the last four, we obtain:

$\mathrm{E}=\mathrm{I} .0 \mathrm{r} 884$ volts, only 2 parts in IOO,000 higher than its certified value.

TABLE XVII.

Electromotive Forces of Clark and Weston Cells, as found by Absolute Determinations.

\begin{tabular}{|c|c|c|c|}
\hline Type of Cell. & $25^{\circ} \mathrm{C}$ & $20^{\circ}$ & $15^{\circ}$ \\
\hline F Series (electrolytic) ............. & 1.01827 & 1.01847 & \\
\hline $\mathrm{E}, \mathrm{K}$ and $\mathrm{O}$ Series (electrolytic) ... & 1.01833 & 1.01853 & \\
\hline C Series (chemical) ............. & 1.01857 & 1.01877 & \\
\hline R Series (electrolytic) ... & 1.42040 & & 1.43296 \\
\hline
\end{tabular}

From this the electromotive forces of the various standard cells compared with the Weston as shown above can be easily found, and are given in Table XVII. 
The value found by the Reichsanstalt for the chemically prepared cadmium cells at $20^{\circ}$ is I.OI86 volts or 0.00017 volt lower.

\section{ELECTROCHEMICAL EQUIVALENT OF SILVER.}

We are now able to calculate the electrochemical equivalent of silver in absolute measure. In a former work ${ }^{1}$ I have determined its value in terms of a Weston cell (No. 804 a B. S.). The emf. of this cell was assumed at that time to be r.or 954 volts at $20^{\circ}$; taking the emf. of a reference Clark as I.434 volts at $15^{\circ}$. By direct comparison with the reference standard No. 813 used in this investigation its emf. was found to be 0.00012 volt lower than No. 813 or I.oI 870 volts at $20^{\circ}$. Its emf. at $20^{\circ}$ as found by the present absolute determination is therefore I.OI 872 volts. The relative value of the electrochemical equivalent found before was I.II683 ing per coulomb, and we obtain therefore as the electrochemical equivalent of silver, when a porous cup coulometer is used,

\section{I.II773 mg per coulomb,}

a result agreeing well with former determinations, except the Frencn (see Table I).

It should be mentioned that it had been my intention to use also a bifilar suspension in this work and that some experiments in this direction had been made, but could not be brought to a conclusion on account of lack of time. The bifilar suspension has the advantage of being free from elastic after-effect, but the calculation of the torsional moment (without the use of a moment of inertia) presents great difficulties, since a slight change in relative tension of the two wires is accompanied by considerable change in the torsional moment. I was also prevented from trying finer suspensions or spiral springs, which might be used by having a part of the load carried by wires which take no part in the torsion. The results obtained in the present investigation are, however, highly satisfactory in showing an agreement among themselves hardly expected, especially between the two different movable coils.

\footnotetext{
${ }^{1}$ Guthe, this Bulletin, 1, 2I; I904.
} 